Revista de Psicología Vol. 30 (2), 2012 (ISSN 0254-9247)

\title{
Vigencia del continuo ideológico izquierda/derecha durante las elecciones presidenciales de 2011 en Lima - Perú
}

\author{
Jan Marc Rottenbacher de Rojas ${ }^{1}$ \\ PUCP, Peru
}

Este estudio analiza la relación entre la ideología política, el comportamiento electoral y las reacciones emocionales luego de las elecciones presidenciales de 2011 en una muestra de adultos de la ciudad de Lima. Se utilizaron escalas de intolerancia a la ambigüedad, necesidad de cierre cognitivo, autoritarismo de ala derecha (RWA) y orientación política de derecha. Un modelo de ecuaciones estructurales propone que la intolerancia a la ambigüedad y la necesidad de cierre cognitivo ejercen una influencia directa sobre el RWA, el mismo que influye positivamente sobre la orientación política de derecha, variable que finalmente influye sobre las reacciones emocionales luego de conocerse el triunfo del candidato Ollanta Humala. Se discute al final acerca de la vigencia contemporánea del continuo ideológico izquierda/derecha.

Palabras clave: comportamiento electoral, orientación política de derecha, autoritarismo, reacciones emocionales

Validity of the ideological left/right continuum during 2011 Presidential Elections in Lima-Peru

This study analyzes the relationship between political ideology, voting behavior and emotional responses after Peruvian presidential elections in 2011. Scales of intolerance for ambiguity, need for closure, right-wing authoritarianism (RWA) and the right-wing political orientation were used to assess right-wing political conservatism. A structural equation model proposes that intolerance of ambiguity and need for closure exert a direct effect on RWA. Also, RWA influences directly the right-wing political orientation, which exerts a direct influence on negative emotional responses and an inverse effect on positive emotional responses after O. Humala's victory. Final discussion focuses on the contemporary relevance of left/right ideological continuum.

Keywords: voting behavior, right-wing political orientation, authoritarianism, emotional responses.

1 Licenciado en Psicología Social y Docente del Departamento de Psicología de la PUCP. Miembro del Grupo de Psicología Política y del Grupo Interdisciplinario de Historia Política Moderna de la PUCP. Dirección Postal: Av. Universitaria 1801, San Miguel, Lima-Perú. Correo electrónico: jrottenbacher@pucp.edu.pe. 

En las elecciones presidenciales del año 2011, las categorías políticas de izquierda y derecha fueron (re)utilizadas para etiquetar, no solo a los candidatos y a sus propuestas políticas, sino también, a los propios simpatizantes o a individuos comunes que mostraban preferencia por una u otra agrupación política, de manera más notoria que en las dos contiendas electorales peruanas anteriores de 2001 y 2006. Es posible sostener que se vivió, por lo menos en la ciudad de Lima, una fuerte polarización entre quienes apoyaban a los candidatos asociados a la derecha y los simpatizantes de la propuesta electoral de Ollanta Humala, vinculado con la izquierda y rotulado como el candidato anti-sistema. Esta fuerte polarización y conflictividad, por lo menos en la ciudad de Lima, ha sido advertida en una trabajo publicado recientemente por Ferrándiz, Ibánez y Espinosa (2011), acerca de los elevados niveles de agresión, prejuicio y racismo que se mostraron en la redes sociales limeñas (facebook o twitter) durante la campańa electoral de 2011. Al final de la segunda vuelta electoral y por un estrecho margen porcentual (ONPE, 2011a), Ollanta Humala resultó vencedor, provocando inmediatamente algunas manifestaciones de miedo entre algunos sectores de la población, especialmente entre los grandes grupos empresariales, los grupos económicamente más privilegiados y sectores políticamente conservadores. Este temor se puede ejemplificar en la caída de la bolsa de valores de Lima al día siguiente de conocerse los resultados electorales.

La expresa polarización política que se vivió en la ciudad de Lima, parece no haberse manifestado en otros departamentos del Perú, en especial en aquellos en los que el actual presidente Ollanta Humala obtuvo un amplio margen de ventaja sobre la otra candidata Keiko Fujimori. En este contexto, el presente estudio se propuso analizar las relaciones entre la ideología política, el comportamiento de los votantes durante las dos vueltas electorales del año 2011 y las reacciones emocionales en una muestra de habitantes de la ciudad de Lima, 
luego de conocerse los resultados finales. Por otro lado, este estudio intentó poner especial énfasis en la orientación política de derecha como una de las variables centrales en el análisis del comportamiento electoral durante las elecciones presidenciales de 2011.

\section{De la izquierda y derecha de Norberto Bobbio al conservadurismo político de derecha}

Desde la Revolución francesa los términos izquierda y derecha han sido utilizados para distinguir dos posiciones ideológicas antagónicas, aparentemente sencillas de comprender, pero que han resultado relativamente difíciles de delimitar (Jost, Federico, \& Napier, 2009). En respuesta a quienes auguraban, hacia comienzos de la década de 1990, el final de la evolución y los antagonismos ideológicos (e. g., Fukuyama, 1992/2006, 1988/1990), Bobbio (1996) indagó en profundidad acerca de los factores ideológicos que subyacen a los términos políticos de izquierda y derecha, lo que le permitió proponer su vigencia dentro de la cultura política del mundo occidental contemporáneo. Bobbio (1996) sostiene que aunque duramente criticados y desprestigiados, los términos izquierda y derecha, utilizados para nombrar posiciones políticas diferenciadas, tienen aún plena vigencia debido a los criterios básicos que los diferencian. La propuesta de Bobbio aunque compleja en su proceso de elaboración, conduce a conclusiones relativamente sencillas. Los dos criterios que distinguen las posiciones ideológicas de izquierda y derecha son: a) la creencia general acerca de la posibilidad de alcanzar la igualdad entre los seres humanos y b) la defensa de las costumbres y la tradición. Según Bobbio (1996), las ideologías o posiciones políticas de derecha consideran que la igualdad entre los seres humanos es una utopía y que lo natural es la existencia de desigualdades entre los grupos y entre las personas.

En ese sentido, la derecha ideológica considera que la desigualdad no solo es un hecho natural, sino que el mismo intento de buscar la igualdad entre las personas resulta siendo perjudicial para el conjunto de la sociedad. Según la derecha ideológica, en busca de la igualdad, 
todos sin excepción, pobres y ricos, jefes y subordinados, poderosos y subalternos, se ven perjudicados (Bobbio, 1996). En contraste, las ideologías de izquierda acogen la creencia de que la igualdad es, en última instancia, alcanzable. La búsqueda de la igualdad y la transformación de la sociedad que implica el conseguirla, son posibles y deseables: la igualdad entre los seres humanos es alcanzable, positiva y, en la mayoría de los casos, para llegar a ella, es necesario ir en contra de la tradición y la costumbres (Bobbio, 1996).

Estas diferencias fundamentales entre izquierda y derecha planteadas por Bobbio (1996) han sido reelaboradas desde la psicología política por diversos autores, quienes han planteado que continúan siendo de suma utilidad práctica para entender el comportamiento político contemporáneo (e. g., Fuchs \& Klingemann, 1990; Jost, 2006; Jost, Glaser, Kruglanski, \& Sulloway, 2003; Thorisdottir, Jost, Liviatan, \& Shrout, 2007). En este sentido, desde la psicología política contemporánea se sostiene que la diferencia ideológica central entre izquierda y derecha radica en la justificación de la inequidad y la defensa de las tradiciones (Greenberg \& Jonas, 2003; Jost et al., 2009; Jost et al., 2003, Thorisdottir et al., 2007).

Bobbio (1996) ampliará su propuesta inicial acerca del continuo izquierda/derecha, incluyendo en la ecuación ideológica el autoritarismo. Los extremismos, tanto de izquierda como de derecha, comparten la tendencia hacia el autoritarismo y rechazan por lo tanto, el igualitarismo. Para Bobbio, la extrema izquierda autoritaria se vio encarnada durante el comunismo estalinista y, por otro lado, la extrema derecha autoritaria estuvo representada por el fascismo y el nazismo. Estos son los dos ejemplos paradigmáticos de todos aquellos casos en los que los extremos de izquierda o derecha han llegado al poder.

En el campo de la psicología política, el autoritarismo de ala derecha (Right Wing Authoritarism, RWA, por sus siglas en inglés) fue introducido como variable psicológica por Altemeyer (1981) a partir del desarrollo sobre la personalidad autoritaria de Adorno, FrenkelBrunswik, Levinson y Sanford (1950). El autoritarismo de ala derecha se expresa a través de tres conjuntos actitudinales: a) la sumisión frente 
a las autoridades que son percibidas como legítimas y frente a las normas que éstas promueven, b) la agresión hacia los grupos que se percibe, se desvían de las normas legítimas y c) el convencionalismo, que lleva a defender las tradiciones y rechazar los cambios sociales abruptos (Altemeyer, 1981, 1988, 1998, 2004; Cottam, Dietz-Uhler, Mastors, \& Preston, 2004; Jost et al., 2003). Entendido de esta manera, pese a estar asociado generalmente con la derecha ideológica, en concordancia con la propuesta de Bobbio (1996) el autoritarismo puede ser una característica tanto de posiciones políticas de izquierda como de derecha. Aunque el tipo de autoritarismo propuesto por Altemeyer se relaciona en especial con la derecha (fundamentalmente en lo referente a la defensa de las tradiciones), Greenberg y Jonas (2003) proponen que, en los regímenes socialistas o comunistas habría sido posible encontrar sistemas tan jerarquizados y personas tan obedientes hacia ellos, que de haber sido evaluadas, hubieran expresado una fuerte tendencia hacia el RWA.

Pese a la importante advertencia de Greenberg y Jonas (2003), en las sociedades occidentales en las que el sistema electoral democrático ha sido adoptado predominantemente luego de la disolución de la URSS en 1991, diversos estudios (e. g., Altemeyer, 2004; Duckitt \& Sibley, 2007; Sidanius, Pratto, Van Laar, \& Levin, 2004) han encontrado evidencia empírica que propone una estrecha relación entre el RWA, la orientación hacia la dominancia social y opciones políticas de derecha, constituyendo juntos, una tendencia ideológico-política que ha sido denominada "conservadurismo de derecha" (Thorisdottir et al., 2007, p. 178). Este tipo de conservadurismo se relaciona con la derecha ideológica planteada por Bobbio (1996), en la medida en que expresa una resistencia al cambio social, y la justificación y aprobación de la inequidad (Jost et al., 2009; Jost et al., 2003; Thorisdottir et al., 2007).

Jost et al. (2003), apoyan la necesidad de indagar acerca de la estructura motivacional subyacente al conservadurismo político y proponen, luego de una amplia revisión meta-analítica (88 muestras de 12 países que conforman en total 22,818 casos), el modelo teórico denominado Conservadurismo Político como Cognición Social Motivada. 
En este modelo, se propone la existencia de tres tipos motivacionales que subyacen y predisponen a las personas a adherirse a posturas ideológicas conservadoras: a) las motivaciones epistémicas, b) las motivaciones existenciales y c) las motivaciones ideológicas o relacionales (Jost et al., 2009; Jost et al., 2003; Van Hiel, Onraet, \& De Pauw, 2010). Adorno et al. (1950) ya habían planteado la necesidad de indagar acerca de los estilos cognitivos que pudiesen predisponer a los individuos a adherirse a ideologías de derecha o de izquierda. Estos autores plantearon la denominada "hipótesis de la rigidez de la derecha" ("rigidity-of-the-right hypothesis", Van Hiel et al., 2010, p. 1766), que hace referencia a la relación directa entre un estilo rígido de procesamiento de la información y la adhesión hacia posturas políticas conservadoras de derecha.

Más recientemente, otros estudios, entre ellos uno realizado en el Perú por Rottenbacher, Espinosa y Magallanes (2011), apoyan que el conservadurismo político se asocia estrechamente con una rigidez cognitiva la cual es entendida como una necesidad de orden, estructura y cierre, una intolerancia a la ambigüedad y una baja tolerancia a la novedad e incertidumbre (e. g., Durrheim, 1998; Federico, Golec, \& Dial, 2005; Jost et al., 2009; Jost et al., 2003; Matthews, Levin, \& Sidanius, 2009; Roets \& Van Hiel, 2010; Van Hiel et al., 2010; Van Hiel, Pandelaere, \& Duriez, 2004). En ese mismo sentido, diversas investigaciones en varios países de occidente, han encontrado de forma consistente, relaciones directas entre una tendencia hacia la derecha política, el RWA, la intolerancia a la ambigüedad y la necesidad de cierre cognitivo, entendidas estas últimas, como dos de las necesidades epistémicas del modelo teórico del Conservadurismo Político como Cognición Social Motivada (e. g., Crowson, Thoma, \& Hestevold, 2005; Jost \& Hunyady, 2005; Jost et al., 2003; Jost, Kruglanski, \& Simon, 1999; McCann, 2008, 2009; Napier \& Jost, 2008; Van Hiel et al., 2010).

Sobre la base de la evidencia empírica que han analizado estos estudios, es posible sostener que el RWA y la orientación política de derecha, así como las necesidades epistémicas que subyacen a ellas, son expresiones de lo que Thorisdottir et al. (2007) denominaron Conservadurismo de Derecha: una posición política que acepta, justifica 
y naturaliza la inequidad entre las personas, y rechaza las transformaciones sociales intentando preservar de esta manera, las convenciones sociales tradicionales.

\section{El rol de las emociones en el comportamiento intergrupal y politico}

Una emoción puede ser definida como una respuesta psicológica de carácter afectivo que tiene correlatos a nivel fisiológico, que cumple funciones adaptativas en dirección a la supervivencia individual y de la especie, que tiene un substrato neurológico, así como una expresión de carácter innato (Izard, 1992, 1991). Se ha propuesto además, que las emociones cumplen una serie de funciones adaptativas en cuatro niveles diferentes de la experiencia humana: a nivel individual, a nivel diádico o interpersonal, a nivel grupal y finalmente, a nivel cultural. Según Keltner y Haidt (1999), en estos cuatro niveles, las emociones estarían dirigidas hacia la regulación de ciertos comportamientos y representaciones mentales, con la finalidad de solucionar los problemas que surgen de forma natural durante la interacción social. Al dar solución a estos problemas de interacción, el ser humano es capaz de adaptarse de forma más exitosa a su mundo social y cultural (Keltner \& Haidt, 1999).

A nivel colectivo, las emociones positivas promueven la cohesión grupal, mientras que las emociones negativas como el miedo hacia miembros de diversos exogrupos ayudan a marcar las diferencias y definir los límites endogrupales (Heise \& O’Brien, 1993; Frijda \& Mesquita, 1994, citados en Keltner \& Haidt, 1999). Asimismo, Plutchik (1980) propuso que cada emoción particular posee una función adaptativa específica; así por ejemplo, el miedo funciona como protector, la alegría promueve la afiliación y la reproducción, la ira se relaciona con la destrucción y el asco promueve el rechazo.

Por otro lado, se ha propuesto que dos de las emociones que ejercen una influencia directa sobre el prejuicio, la discriminación y algunas actitudes sociopolíticas, son el miedo (Stephan \& Stephan, 1996, 1993; Velasco, Verkuyten, Weesie, \& Poppe, 2008) y el asco (Hodson \& Costello, 2007; Rozin, Markwith, \& McCauley, 1994; Schaller, Park, \& 
Faulkner, 2003). Según la Teoría Integrada de la Amenaza (ITT, por sus siglas en inglés) desarrollada por Stephan y Stephan (1996, 1993), el miedo a nivel intergrupal surge de la percepción de amenazas realistas o simbólicas en contra de la identidad, cultura o forma de vida del endogrupo. Diversos estímulos sociales pueden generar estos dos tipos de amenazas que se percibe, atentarán de forma real o simbólica contra la integridad del endogrupo a nivel físico, económico, social o cultural (Stephan \& Stephan, 1996, 1993; Velasco et al., 2008). La percepción de amenaza genera estereotipia negativa, prejuicio y hostilidad hacia el grupo o estímulo social percibido como amenazante, con la finalidad de alejarlo o destruirlo, y con ello eliminar la sensación de miedo (Velasco et al., 2008). Según Oesterreich (2005), la percepción de amenaza puede desencadenar, sobretodo en los individuos con una marcada tendencia hacia el RWA, lo que denominó la respuesta autoritaria, es decir, actitudes autoritarias y hostiles contra todo estímulo que represente algún tipo de riesgo.

Así como el miedo posee la función básica de proteger al individuo de posibles riesgos que atenten contra su integridad o la del endogrupo, se ha propuesto que el asco posee una función similar al proteger al individuo contra la exposición hacia determinados ambientes, objetos o personas que pudieran ser nocivas para la salud (Hodson \& Costello, 2007; Rozin et al., 1994; Schaller et al., 2003). Hodson \& Costello (2007) proponen además, que el asco se racionaliza en forma de rechazo o distanciamiento hacia algún individuo o grupo, cuando interactúa con variables ideológicas como el RWA o la orientación hacia la dominancia social.

En términos generales, se puede sostener que tanto el miedo como el asco son emociones básicas, que filogenéticamente han cumplido funciones adaptativas dirigidas hacia la protección física de los seres humanos y que, con el desarrollo de la civilización y la complejización de la sociedad, han sido racionalizadas en una forma discursiva (o ideológica) que justifica la sensación de miedo y asco hacia determinados estímulos sociales, sean estos grupos o individuos (Hodson \& Costello, 2007; Velasco et al., 2008). 
En un contexto electoral, según Marcus y MacKuen (1993/2004), un candidato o una propuesta política pueden producir miedo o rechazo, cuando representan una amenaza hacia nuestro mundo simbólico, es decir, hacia nuestros valores y creencias; o hacia nuestro mundo real (i. e., situación económica, seguridad familiar, libertad de circulación geográfica, etc.). En estos casos, el miedo o rechazo originados por estas amenazas no deben ser entendidos como emociones primitivas que se activan ante una amenaza física, sino que reflejan una compleja interacción entre los procesos cognitivos y las emociones lo que resulta más útil para la comprensión del comportamiento político (Espinosa, 2008; Marcus \& MacKuen, 1993/2004).

\section{El contexto electoral peruano durante 2011}

Como se mencionó en la introducción, las elecciones presidenciales peruanas de 2011 se caracterizaron, por lo menos en Lima, por presentar altos niveles de conflictividad y polarización, tanto a nivel de los medios de comunicación como de las redes sociales y la opinión pública. Ataques de diversos tipos, así como mensajes prejuiciosos o racistas fueron lanzados hacia una u otra opción política y sus adeptos (Ferrándiz et al., 2011). Otro fenómeno importante de mencionar fue la reaparición de los términos izquierda y derecha para catalogar a los diversos actores políticos y a los grupos que los apoyaban (Dargent, 2011). Si bien este estudio no tiene como objetivo central analizar el panorama electoral de 2011, su dinámica o evolución, es necesario brindar información básica para el lector acerca de los cuatro candidatos que obtuvieron el mayor porcentaje de votos en la primera vuelta: Ollanta Humala, Keiko Fujimori, Pedro Pablo Kuczynski y Alejandro Toledo (ONPE, 2011b).

El primer lugar, Ollanta Humala, líder de la agrupación Gana Perú, agrupó para su candidatura a algunos personajes vinculados a los partidos tradicionales de la izquierda peruana. Además de esto, una supuesta alianza con el régimen del presidente venezolano Hugo Chávez y sus propuestas acerca de la redistribución equitativa de la riqueza, influyeron sobre la opinión pública limeña, que lo ubicó casi 
inmediatamente dentro del panorama político como el candidato de la izquierda. Como ya se mencionó, Humala fue considerado además, la opción política anti-sistema, debido principalmente, a una supuesta vinculación con la izquierda radical peruana (Caballero, 2010) y a sus propuestas de cambio sustancial en el modelo económico neoliberal, vigente en el Perú desde la década de 1990.

Desde su primera postulación a la presidencia en 2006, Humala fue calificado como anti-sistema, por su posición política y porque sus planteamientos podían representar una amenaza contra la estabilidad social, política y económica del país (Vela, 2006). En un estudio empírico desde la psicología política, Espinosa (2008) encontró que durante las elecciones de 2006, la posibilidad de que Humala se convirtiera en presidente del Perú generó, en una muestra limeńa, altos niveles de miedo. Asimismo, en aquel estudio se propuso que el miedo hacia Ollanta Humala estaba condicionado por la creencia generalizada y difundida a través de los medios de comunicación, de que Humala significaba una grave amenaza contra el sistema económico y social establecido. Esta percepción de amenaza y el miedo que provocó en algunos sectores de la sociedad peruana, favoreció en 2006, la victoria electoral de Alan García Pérez (Espinosa, 2008), quien pese a haber realizado una de las peores gestiones presidenciales de las últimas cuatro décadas, resultó elegido por segunda vez para ocupar la Presidencia de la República durante el período 2006-2011.

En la otra orilla política, debido a sus planteamientos económicos neoliberales y a sus vinculaciones con personajes e instituciones políticas conservadoras, en 2011 los candidatos que podían representar a la derecha política eran Pedro Pablo Kuczynski y Keiko Fujimori (Dargent, 2011). El caso de Kuczynski es bastante llamativo en la medida en que, por lo menos en Lima, fue el candidato que presentó el mayor crecimiento en la intención de voto, en especial hacia el último mes previo a la primera vuelta electoral. Kuczynski fue Ministro de Economía durante el gobierno de Alejandro Toledo y ganó una buena reputación entre algunos sectores sociales debido a su pragmatismo en materia económica y a una aparente asepsia ideológica, lo que ayudó 
a proyectar una imagen de especialista-técnico no politizado. Su agrupación electoral de 2011, denominada Alianza por el Gran Cambio, era un conjunto de pequeñas y diversas agrupaciones, tan disímiles entre sí, que apenas concluyeron las elecciones, la alianza se disolvió, lo que sugeriría que esta agrupación era, según la propuesta de Panebianco (1982), un tipo de partido poco ideologizado y orientado básicamente a conseguir una victoria electoral.

Durante 2011, Kuczynski ganó muchos adeptos, en especial entre los jóvenes limeños con niveles socioeconómicos y educativos medios y altos. Se puede proponer que estos jóvenes se habían visto beneficiados con las políticas económicas neoliberales implementadas en el Perú desde la década de 1990, las mismas que han propiciado un crecimiento macroeconómico bastante notorio desde 2001 en adelante (Jiménez, 2000; Tanaka, 2011). Después de la primera vuelta, Kuczynski (2012) instó a sus simpatizantes a votar por Keiko Fujimori "para detener la amenaza" que significaría un gobierno de Ollanta Humala.

Keiko Fujimori, hija del ex-presidente Alberto Fujimori, fue la segunda candidata con mayor votación tanto en la primera como en la segunda vuelta electoral. La herencia del gobierno de su padre significaba paradójicamente, el origen del masivo apoyo político con el que contaba y el principal argumento en contra utilizado por sus oponentes. Durante el gobierno autoritario de Alberto Fujimori (1990-2000) se había conseguido derrotar al terrorismo de Sendero Luminoso y del Movimiento Revolucionario Túpac Amaru (MRTA), y se había logrado sacar al Perú de la aguda crisis económica y social de la década de 1980-1990. Estos dos logros realizados durante el gobierno de su padre, fueron utilizados por Keiko Fujimori y su agrupación política Fuerza 2011, como sus principales banderas políticas. Sin embargo, Alberto Fujimori y algunos de los más altos funcionarios de su régimen se encuentran actualmente condenados por crímenes de lesa humanidad, violación de los derechos humanos o corrupción. Si bien los logros del régimen fujimorista durante la década de 1990, otorgaban argumentos a favor de la postulación de su hija Keiko, los actos de corrupción generalizada y el carácter dictatorial del régimen, 
representaban antecedentes sumamente negativos con los que la candidatura de Keiko Fujimori debió cargar.

Resulta más difícil precisar quiénes eran los seguidores o simpatizantes de la candidatura de Keiko Fujimori. Solo es posible proponer de forma hipotética que eran personas de diversa extracción social, proclives a las medidas económicas y sociales de corte pragmático, con cierta tendencia hacia el autoritarismo como medio para solucionar los problemas del país y con algún nivel de miedo con respecto al desorden social que pudiese producir la victoria de un candidato como Ollanta Humala. En ese sentido, es posible proponer, que la mayoría de los simpatizantes de Keiko Fujimori, podrían haber presentado una tendencia hacia el RWA y una orientación política de derecha.

En una posición que ha sido denominada de centro (Bobbio, 1996), podríamos ubicar al ex-presidente Alejandro Toledo, quien pese a haber continuado con el modelo económico neoliberal inaugurado por el régimen de Alberto Fujimori, fue la figura que encabezó, durante el año 2000, un movimiento social que, entre otros factores, llevaría a su fin los diez años de gobierno fujimorista.

En este contexto descrito de forma muy general, izquierda y derecha fueron utilizadas respectivamente como sinónimos de anti-sistema y pro-sistema, comunismo y capitalismo, estatismo y neoliberalismo económico. Fuchs y Klingemann (1990) ya había encontrado que estos conceptos políticos son algunos de los que suelen asociarse semánticamente cuando las personas se representan la izquierda y la derecha en términos políticos. En este sentido, una de las principales banderas electorales de Ollanta Humala fue la necesidad de una distribución más equitativa de la riqueza en un país que, habiendo logrado cierto grado de crecimiento económico, requería distribuirlo de forma más equilibrada (Mendoza, 2011). Esta apuesta por la equidad social y económica, es lo que a partir de la propuesta de Bobbio (1996), ubicaría a Ollanta Humala a la izquierda, mientras que la apuesta por el neoliberalismo económico, el pragmatismo y ciertos niveles de autoritarismo (en el caso del fujimorismo), ubicarían a Keiko Fujimori y a Pedro Pablo Kuczynski a la derecha política. 
Sobre la base de la revisión bibliográfica realizada, este estudio se propone analizar las relaciones entre: a) el conservadurismo de derecha, evaluado a través del RWA, la orientación política de derecha, la intolerancia a la ambigüedad y la necesidad de cierre cognitivo, b) las preferencias electorales en la primera y segunda vuelta, y c) las reacciones emocionales posteriores al resultado final de las elecciones presidenciales del Perú en 2011.

En primer lugar, se analizará mediante el uso de tablas de contingencia, el comportamiento electoral entre la primera y segunda vuelta, así como la relación entre el conservadurismo de derecha y el voto en la segunda vuelta. En segundo lugar, utilizando diagramas estructurales (SEM, por su siglas en inglés), las relaciones entre las variables serán analizadas a partir de tres hipótesis: la primera $\left(H_{I}\right)$ propone que la intolerancia a la ambigüedad y la necesidad de cierre cognitivo, correlacionadas entre sí de forma positiva, deben ejercer ambas una influencia directa sobre el RWA y sobre la orientación política de derecha. La segunda hipótesis $\left(H_{2}\right)$ propone que el RWA debe ejercer una influencia directa sobre la orientación política de derecha. Finalmente, la tercera hipótesis $\left(H_{3}\right)$ plantea que tanto el RWA como la orientación política de derecha deben ejercer una influencia directa sobre las reacciones emocionales de miedo, desprecio y asco luego de la victoria electoral de Ollanta Humala, y a la vez, una influencia inversa sobre las reacciones emocionales de alegría e interés.

\section{Método}

\section{Participantes}

Con la finalidad de reclutar a los participantes del estudio, se utilizó un tipo de muestreo no-probabilístico intencional. Todos los participantes de este estudio eran adultos de la ciudad de Lima $(N=383)$, cuyas edades fluctuaban entre un mínimo de 18 y un máximo de 59 años $(M E=26.77, D E=7.66)$. El $49.6 \%$ eran hombres y el $50.4 \%$ 
mujeres. Con respecto a su nivel educativo, el $54.6 \%$ eran estudiantes universitarios, un $25.6 \%$ poseía estudios universitarios completos, un 6.5\% estudios técnicos completos, el 6.0\% estudiaba alguna carrera técnica, el $5.7 \%$ poseía estudios de posgrado y solo un $1.6 \%$ había concluido únicamente la secundaria. El $63.4 \%$ se ubicó en un nivel socioeconómico (NSE) medio, el $24 \%$ en un NSE medio alto, un 8.7\% en un NSE medio bajo, el 3.4 en un NSE alto y solo un 0.3 en un NSE bajo. En general, los participantes eran residentes de 29 distritos de la ciudad de Lima y el Callao.

\section{Instrumentos y medidas}

1. Intolerancia a la Ambigüedad. Se utilizó la versión en idioma español de la Escala de Tolerancia a la Ambigüedad (MSTAT-II), de Arquero y McLain (2010). Esta escala está compuesta de 13 ítems cuya opción de respuesta es una escala Likert de 6 puntos donde: 1 = "Totalmente en desacuerdo" y 6 = "Totalmente de acuerdo". La escala presentó un alto nivel de confiabilidad para el caso de la muestra $(\alpha=.87)$.

2. Necesidad de Cierre Cognitivo. Se utilizó una versión traducida al castellano de la escala denominada Need for Closure Scale de Roets y Van Hiel (2010). El instrumento está compuesto de 15 ítems cuya opción de respuesta es una escala Likert de 6 puntos donde: 1 = "Totalmente en Desacuerdo" y 6 = "Totalmente de Acuerdo". La escala presentó un alto nivel de confiabilidad para el caso del presente estudio $(\alpha=.84)$.

3. RWA. Se utilizó una versión traducida al castellano por Rottenbacher y Schmitz (2012, en prensa) de la versión reducida de la Escala de Autoritarismo de Ala Derecha (RWA) de Zakrisson (2005). Esta escala está compuesta de 15 ítems cuya opción de respuesta es una escala Likert de 6 puntos en la que: 1 = "Totalmente en desacuerdo" y 6 = "Totalmente de acuerdo". El nivel de confiabilidad de la escala resultó alto para el caso del presente estudio $(\alpha=.83)$.

4. Orientación Política de Derecha. Se utilizó un solo ítem, cuya opción de respuesta fue una escala Likert de siete puntos en la que: 1 = "De izquierda" y 6 = "De derecha". Se les pidió a los participantes 
que se ubicaran en algún punto de este continuo, según consideraran ellos mismos su posición política en esos términos. Un puntaje mayor a la media teórica $(M T=3)$ expresa una orientación política de derecha.

\section{Respuestas emocionales luego de los resultados electorales.} Se utilizó una escala adaptada de cinco emociones a partir de la propuesta de las diez emociones básicas de Izard (1991), utilizada con éxito en el contexto limeño por Espinosa (2008). Las cinco emociones evaluadas fueron: Alegría, Interés, Asco, Desprecio y Miedo. Se pidió a los participantes que indicaran en qué grado habían experimentado cada una de estas cinco emociones al momento de conocer los resultados de la segunda vuelta electoral en la que resultó ganador el candidato presidencial Ollanta Humala. La opción de respuesta es una escala Likert de 5 puntos donde: 1 = "Nada" y 5 = "Mucho".

\section{Procedimiento}

Se elaboró el cuestionario que contenía el consentimiento informado, los instrumentos para la medición de las variables de estudio, así como una sección para consignar los datos sociodemográficos. Se contactó a los participantes en el campus universitario de la Pontificia Universidad Católica del Perú (PUCP) y a través de contactos personales. 25 estudiantes de la carrera de psicología social de la PUCP fueron capacitados y colaboraron en la recolección de la información. Todos los participantes recibieron el cuestionario de manera voluntaria y en todo momento se les recordó que podían finalizar el llenado de las encuestas si así lo deseaban. A través de este procedimiento se obtuvo una muestra de 279 participantes. En paralelo a esta aplicación presencial, se creó un cuestionario virtual a través de la plataforma libre Google Docs. Se envió el enlace de la encuesta virtual a diversos contactos personales por correo electrónico quienes compartieron el enlace en sus páginas de facebook. En tres semanas se logró conseguir un total de 104 encuestas completas. Al integrar ambas bases se obtuvo la muestra final de 383 participantes. La información fue recolectada entre agosto y setiembre de 2011. Los datos obtenidos fueron analizados utilizando el software estadístico SPSS ${ }^{\odot} 19$ y el paquete $\operatorname{AMOS}^{\odot} 20$. 


\section{Resultados}

\section{Comportamiento electoral de la muestra}

Sobre la base del estadístico Chi-cuadrado $\left(\chi^{2}(24)=223.185\right.$, $p<.0001)$, se puede sostener que existen diferencias significativas en la distribución de las proporciones que aparecen en la primera tabla de contingencia (ver Tabla 1). Se puede apreciar que el 25.7\% de la muestra votó por Pedro Pablo Kuczynski en la primera vuelta y por Keiko Fujimori en la segunda. Asimismo, se puede apreciar que el $22.8 \%$ votó por Alejandro Toledo en la primera vuelta y por Ollanta Humala en la segunda. El 15.2\% voto por Kuczynski en la primera vuelta y por Humala en la segunda, mientras que solo el 3.4\% votó por A. Toledo en la primera vuelta y por K. Fujimori en la segunda. En términos generales, la Tabla 1 muestra la migración del voto por Alejandro Toledo en primera vuelta hacia Ollanta Humala en la segunda, así como el voto por Kuczynski en la primera vuelta hacia Keiko Fujimori en la segunda.

\section{Tabla 1}

Variación del voto entre la primera y la segunda vuelta electoral

\begin{tabular}{lcccccc}
\hline \multirow{2}{*}{$\begin{array}{l}\text { Voto en la primera } \\
\text { vuelta electoral }\end{array}$} & \multicolumn{5}{c}{ Voto en la segunda vuelta electoral } & \\
\cline { 2 - 6 } & $\begin{array}{c}\text { Ollanta } \\
\text { Humala }\end{array}$ & $\begin{array}{c}\text { Kujiko } \\
\text { Alejando Toledo }\end{array}$ & $\begin{array}{c}\text { Voté en } \\
\text { blanco }\end{array}$ & $\begin{array}{c}\text { Vicié } \\
\text { mi voto }\end{array}$ & $\begin{array}{c}\text { No } \\
\text { votén }\end{array}$ & \\
\hline Pedro Pablo Kuczynski & $22.8 \%$ & $3.4 \%$ & $0.3 \%$ & $1.8 \%$ & $0.3 \%$ & $28.6 \%$ \\
Ollanta Humala & $6.6 \%$ & $0.0 \%$ & $0.0 \%$ & $0.0 \%$ & $0.0 \%$ & $6.6 \%$ \\
Keiko Fujimori & $0.0 \%$ & $3.1 \%$ & $0.0 \%$ & $0.3 \%$ & $0.0 \%$ & $3.4 \%$ \\
Otro candidato & $0.8 \%$ & $1.3 \%$ & $0.3 \%$ & $0.0 \%$ & $0.3 \%$ & $2.6 \%$ \\
Voté en blanco & $0.3 \%$ & $0.3 \%$ & $1.0 \%$ & $0.0 \%$ & $0.0 \%$ & $1.6 \%$ \\
Vicié mi voto & $0.8 \%$ & $0.5 \%$ & $0.0 \%$ & $1.8 \%$ & $0.0 \%$ & $3.1 \%$ \\
\hline Total & $46.5 \%$ & $34.4 \%$ & $4.5 \%$ & $14.2 \%$ & $0.5 \%$ & $100.0 \%$ \\
\hline
\end{tabular}




\section{Relaciones entre la rigidez cognitiva, la ideología política y el comportamiento electoral}

Con el objetivo de analizar la relación entre la rigidez cognitiva, la ideología política y el comportamiento electoral se realizaron tres análisis de conglomerados bietápicos. En el primero, se utilizaron las variables vinculadas con la rigidez cognitiva: la Intolerancia a la Ambigüedad y la Necesidad de Cierre Cognitivo. En el segundo, se utilizó el RWA y finalmente, en el tercer análisis, se utilizó la Orientación Política de Derecha. A través del primer análisis de conglomerados se obtuvo dos grupos: el primero fue denominado "Más cognitivamente rígidos", por obtener mayores puntajes en la Intolerancia a la Ambigüedad y la Necesidad de Cierre Cognitivo, en comparación con los "Menos cognitivamente rígidos".

En el segundo análisis se formaron dos conglomerados denominados "Más autoritarios", por obtener puntuaciones más elevadas en el RWA, en comparación con el grupo denominado "Menos autoritarios". En el tercer análisis se obtuvo dos conglomerados denominados "De izquierda", por puntuar menos en la Orientación Política de Derecha, en comparación con los denominados "De derecha". El detalle de los conglomerados identificados de puede observar en la Tabla 6 (ver Apéndice 1).

Las Tablas 2, 3 y 4 presentan los resultados de tres tablas de contingencia que han cruzado las proporciones de los conglomerados identificados y el voto de la muestra en la segunda vuelta electoral del año 2011. 


\section{Tabla 2}

Conglomerados según rigidez cognitiva y voto en la segunda vuelta electoral

\begin{tabular}{lcccccc}
\hline \multirow{2}{*}{ Conglomerados } & \multicolumn{5}{c}{ Voto en la segunda vuelta electoral } & \\
\cline { 2 - 5 } & $\begin{array}{l}\text { Ollanta } \\
\text { Humala }\end{array}$ & $\begin{array}{c}\text { Keiko } \\
\text { Fujimori }\end{array}$ & $\begin{array}{c}\text { Voté en } \\
\text { blanco }\end{array}$ & $\begin{array}{c}\text { Vicié } \\
\text { mi voto }\end{array}$ & $\begin{array}{c}\text { No } \\
\text { votén }\end{array}$ & \\
\hline $\begin{array}{l}\text { 1. "Más cognitivamente } \\
\text { rígidos" }\end{array}$ & $18.2 \%$ & $19.0 \%$ & $3.2 \%$ & $4.7 \%$ & $0.0 \%$ & $45.1 \%$ \\
$\begin{array}{l}\text { 2. "Menos } \\
\text { cognitivamente } \\
\text { rígidos" }\end{array}$ & $23.3 \%$ & $20.6 \%$ & $2.0 \%$ & $8.3 \%$ & $0.8 \%$ & $54.9 \%$ \\
\hline Total & $41.5 \%$ & $39.5 \%$ & $5.1 \%$ & $13.0 \%$ & $0.8 \%$ & $100.0 \%$ \\
\hline
\end{tabular}

Según el estadístico Chi-cuadrado no se puede sostener que haya diferencias significativas entre las proporciones que se observan en la Tabla $2\left(\chi^{2}(4)=4.490, p=.344\right)$. Esto se puede observar en las proporciones obtenidas: el 18.2\% de la muestra, siendo "Más cognitivamente rígidos" votó por Humala, mientras que el 19.0\% de la muestra votó por Keiko Fujimori, siendo igualmente "Más cognitivamente rígidos". Lo mismo sucede con los "Menos cognitivamente rígidos": el 23.3\% de la muestra votó por Humala mientras el 20.6\% lo hizo por Keiko.

\section{Tabla 3}

Conglomerados según RWA y voto en la segunda vuelta electoral

\begin{tabular}{|c|c|c|c|c|c|c|}
\hline \multirow[b]{2}{*}{ Conglomerados } & \multicolumn{5}{|c|}{ Voto en la segunda vuelta electoral } & \multirow[b]{2}{*}{ Total } \\
\hline & $\begin{array}{l}\text { Ollanta } \\
\text { Humala }\end{array}$ & $\begin{array}{l}\text { Keiko } \\
\text { Fujimori }\end{array}$ & $\begin{array}{l}\text { Voté en } \\
\text { blanco }\end{array}$ & $\begin{array}{c}\text { Vicié } \\
\text { mi voto }\end{array}$ & $\begin{array}{c}\text { No } \\
\text { voté }\end{array}$ & \\
\hline 1. "Menos autoritarios" & $25.7 \%$ & $14.2 \%$ & $1.1 \%$ & $6.6 \%$ & $0.5 \%$ & $48.1 \%$ \\
\hline 2. "Más autoritarios" & $20.5 \%$ & $19.9 \%$ & $3.6 \%$ & $7.9 \%$ & $0.0 \%$ & $51.9 \%$ \\
\hline Total & $46.2 \%$ & $34.2 \%$ & $4.6 \%$ & $14.5 \%$ & $0.5 \%$ & $100.0 \%$ \\
\hline
\end{tabular}


Según el valor del estadístico Chi-cuadrado, sí se puede sostener que existen diferencias significativas entre las proporciones presentadas en la Tabla $3\left(\chi^{2}(4)=12.383, p=.015\right)$. Mientras un $25.7 \%$ de la muestra, siendo "Menos autoritarios" votó por Humala, un 14.2\% votó por Keiko. En contraste, en el conglomerado denominado "Más autoritarios" el voto por Ollanta Humala y Keiko Fujimori es bastante más homogéneo (20.5\% y $19.9 \%$, respectivamente). Asimismo, un mayor porcentaje del conglomerado denominado "Más autoritarios" votó en blanco o vició su voto durante la segunda vuelta.

\section{Tabla 4}

Conglomerados según Orientación Politica de Derecha y voto en la segunda vuelta electoral

\begin{tabular}{lcccccc}
\hline \multirow{2}{*}{ Conglomerados } & \multicolumn{5}{c}{ Voto en la segunda vuelta electoral } & \\
\cline { 2 - 6 } & $\begin{array}{c}\text { Ollanta } \\
\text { Humala }\end{array}$ & $\begin{array}{c}\text { Kujiko } \\
\text { Fujimori }\end{array}$ & $\begin{array}{c}\text { Voté en } \\
\text { blanco }\end{array}$ & $\begin{array}{c}\text { Vicié } \\
\text { mi voto }\end{array}$ & $\begin{array}{c}\text { No } \\
\text { votén }\end{array}$ & \\
\hline 1. "De derecha" & $17.3 \%$ & $23.8 \%$ & $2.5 \%$ & $7.4 \%$ & $0.5 \%$ & $51.5 \%$ \\
2. "De izquierda" & $29.0 \%$ & $9.9 \%$ & $2.2 \%$ & $7.4 \%$ & $0.0 \%$ & $48.5 \%$ \\
\hline Total & $46.3 \%$ & $33.7 \%$ & $4.7 \%$ & $14.8 \%$ & $0.5 \%$ & $100.0 \%$ \\
\hline
\end{tabular}

Según el estadístico Chi-cuadrado, también se puede sostener que existen diferencias significativas entre las proporciones que se presentan en la Tabla $4\left(\chi^{2}(4)=33.845, p<.0001\right)$. Mientras el $29.0 \%$ de la muestra, siendo "De izquierda" votó por Humala, solo el 9.9\% lo hizo por Keiko Fujimori. Asimismo, mientras el $17.3 \%$ de la muestra, pudiendo ser denominado "De derecha" votó por Humala; el 23.8\% lo hizo por Keiko Fujimori y se incluye dentro del conglomerado denominado "De derecha". Se observa además, que la distribución entre el voto de K. Fujimori y $\mathrm{O}$. Humala es más homogénea en el caso de los "De derecha", en contraste con los "De izquierda" donde se aprecia una marcada tendencia hacia el voto por Ollanta Humala. 
Sobre la base de los resultados de las tres tablas de contingencia (ver Tablas 2, 3 y 4), se puede sostener que en la Tabla 4 se aprecian de forma más clara, diferencias significativas entre las proporciones observadas.

\section{Análisis de correlación paramétrica: rigidez cognitiva, ideología política y reacciones emocionales luego de la segunda vuelta electoral}

En la Tabla 5 se muestra la matriz de correlación paramétrica entre las nueve variables de este estudio. Las correlaciones de mayor intensidad se presentaron entre el Asco y el Desprecio en el triunfo de O. Humala, entre el Miedo y el Desprecio en el triunfo de O. Humala y entre la Intolerancia a la Ambigüedad y la Necesidad de Cierre Cognitivo. Por otro lado, el RWA y la Orientación Política de Derecha son las dos variables que presentan correlaciones significativas con todas las demás variables del estudio. 


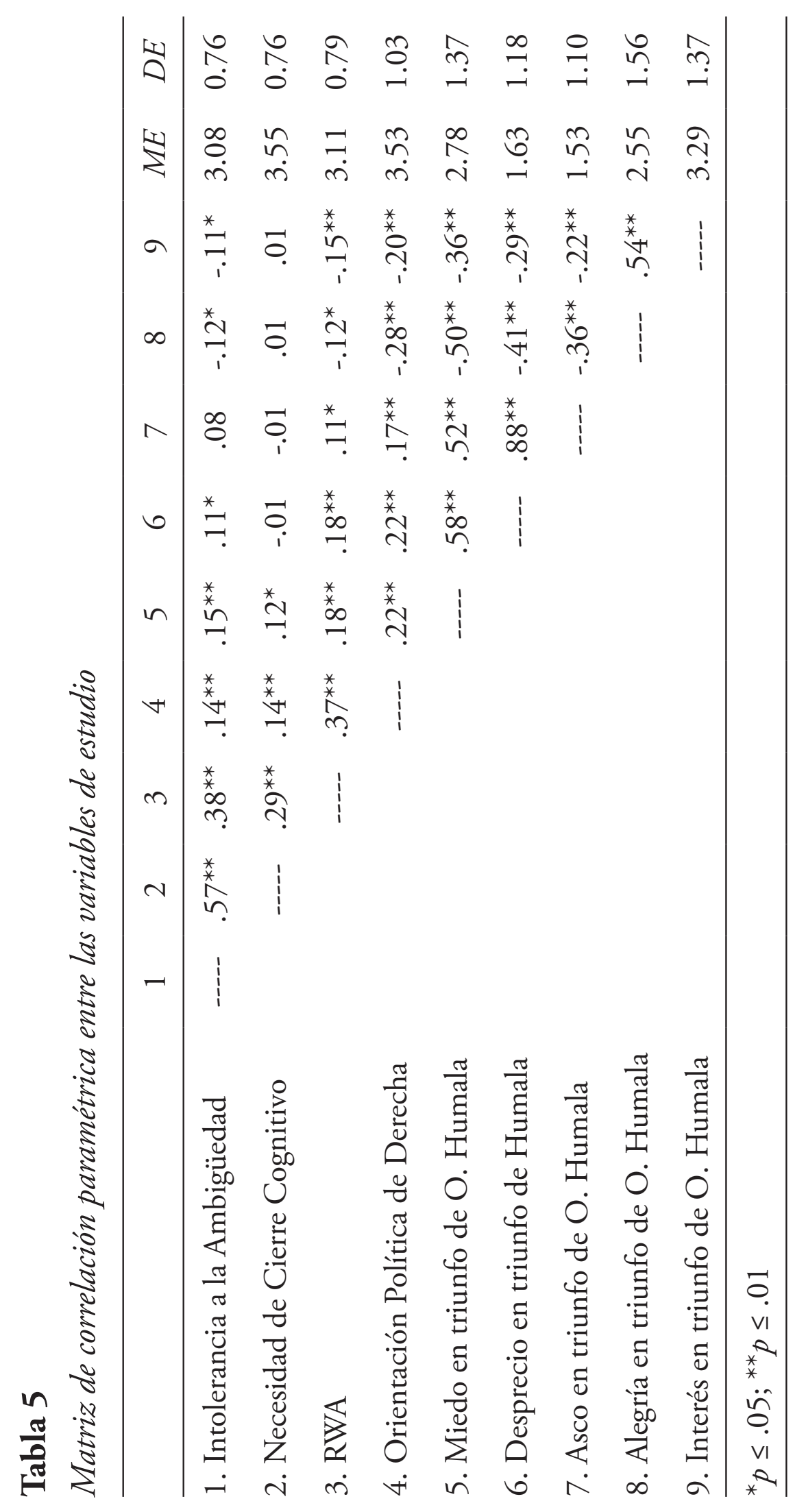




\section{Análisis de ecuaciones estructurales: rigidez cognitiva, ideología política y reacciones emocionales luego de los resultados de la segunda vuelta electoral}

Se contrastó un diagrama estructural hipotético (Modelo 1), basado en las tres hipótesis del estudio (ver Figura 1). Según los indicadores de ajuste propuestos por diversos autores (e. g., Bollen, 1989; Kline, 2005; Ruiz, Pardo, \& San Martín, 2010; Schumacker \& Lomax, 2004), el Modelo 1 no presentó un adecuado grado de ajuste con respecto a los datos: $\chi^{2} / g l=13.128, \mathrm{CFI}=.798, \mathrm{NFI}=.790, \mathrm{TLI}=.546, \mathrm{IFI}=.802$, RMSEA $=.178(90 \% \mathrm{CI}=.159 \leq .178 \leq .198)$. Además, varias de las relaciones de influencia propuestas no resultaron significativas: ni la Intolerancia a la Ambigüedad, ni la Necesidad de Cierre ejercieron influencia significativa sobre la Orientación Política de Derecha.

El RWA no ejerció influencia significativa, ni sobre el Asco en el triunfo de O. Humala, ni sobre la Alegría en el triunfo de O. Humala. Finalmente, la Orientación Política de Derecha no ejerció influencia significativa sobre la reacción emocional de Interés luego del triunfo de O. Humala. Por estos motivos, se diseńó y contrastó un modelo alternativo (Modelo 2), en el que se modificaron las relaciones entre las variables, privilegiando el rol de la Orientación Política de Derecha como determinante de las reacciones emocionales frente a la victoria del candidato presidencial Ollanta Humala y atribuyendo un rol central al miedo como determinante directo del desprecio y condicionante inverso de la alegría luego del triunfo de $\mathrm{O}$. Humala.

El modelo alternativo (ver Figura 2) obtuvo un buen ajuste con respecto a los datos y todas las relaciones propuestas resultaron significativas. Aunque según el valor del estadístico Chi-cuadrado y su grado de significación, no se puede sostener que todos los errores del modelo son iguales a cero $\left(\chi^{2}(27)=43.566, p=.023\right)$, los demás indicadores permiten sostener que el Modelo 2 presenta un buen grado de ajuste con respecto a los datos: $\chi^{2} / g l=1.614, \mathrm{CFI}=.986, \mathrm{NFI}=.965$, $\mathrm{TLI}=.977, \mathrm{IFI}=.986, \mathrm{RMSEA}=.040(90 \% \mathrm{CI}=.015 \leq .040 \leq .061)$. 


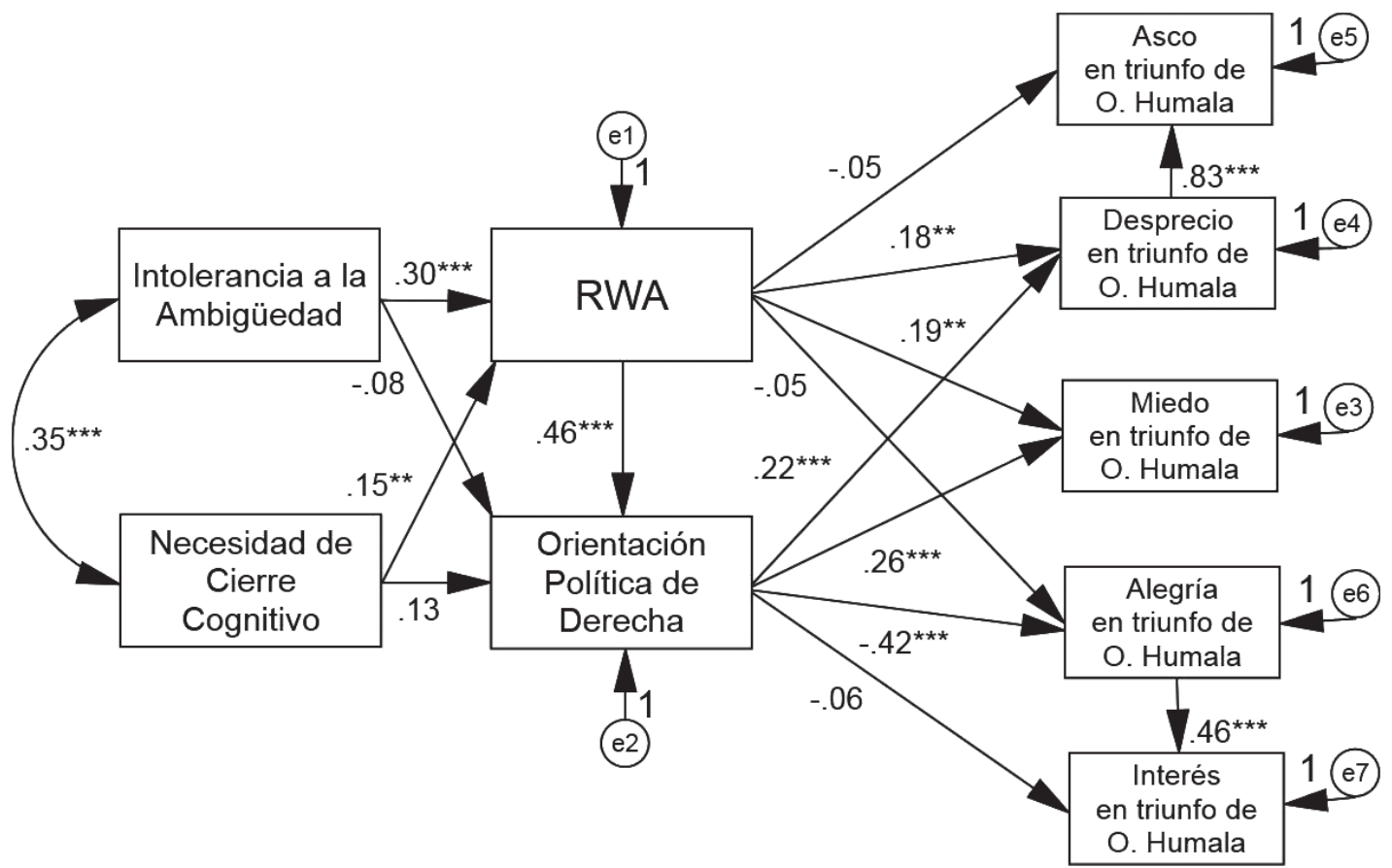

Figura 1. Diagrama estructural del modelo hipotético (Modelo 1) ${ }^{* *} p<.05 ;{ }^{* * *} p<.001$

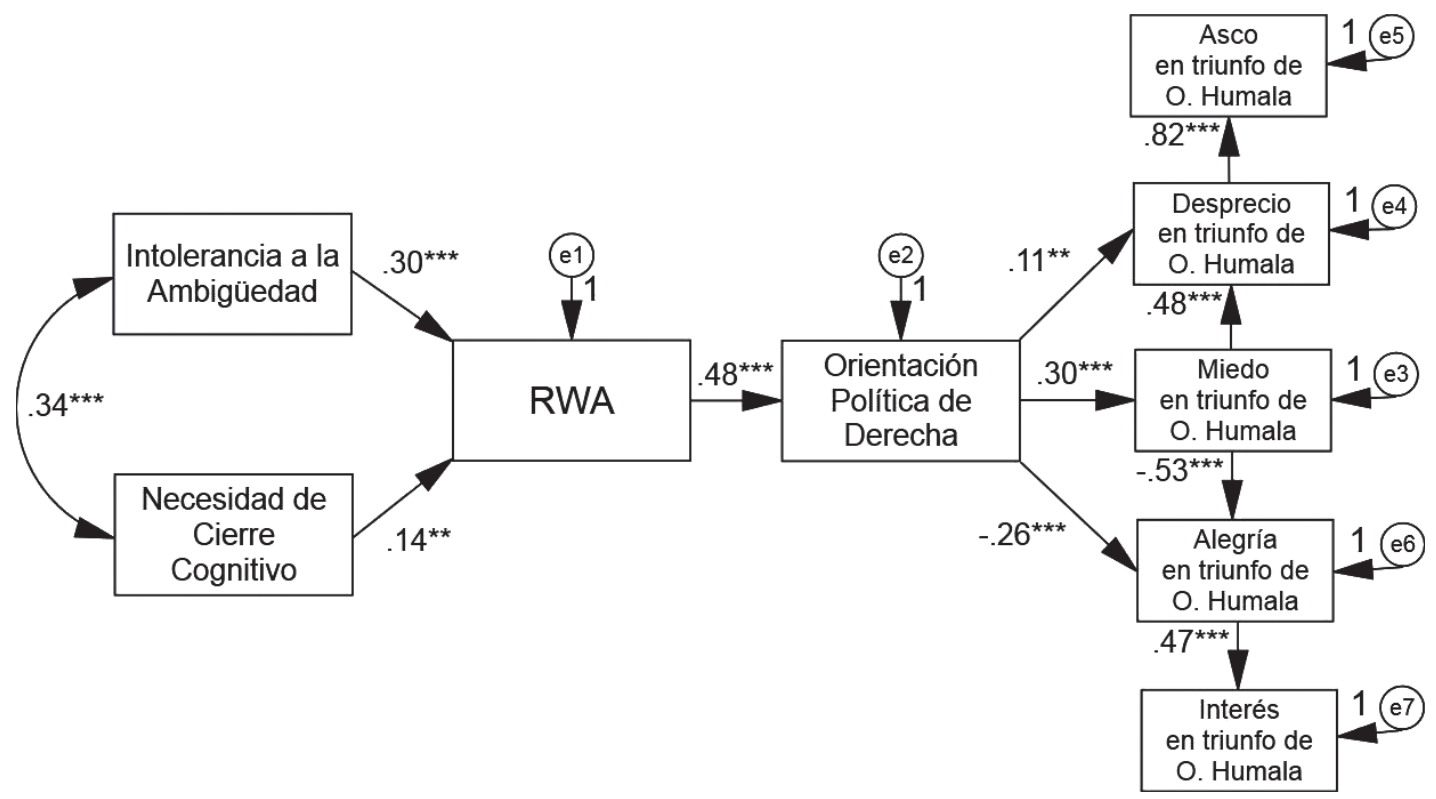

Figura 2. Diagrama estructural del modelo alternativo (Modelo 2)

${ }^{* *} p<.05 ;{ }^{* * *} p<.001$ 


\section{Discusión}

\section{Comportamiento electoral entre la primera y segunda vuelta}

Como se ha podido observar en los resultados, el voto favorable a Pedro Pablo Kuczynski, migró en la segunda vuelta hacia Keiko Fujimori, mientras que el voto favorable a Alejandro Toledo migró principalmente hacia Humala en la segunda vuelta. Estos resultados son consistentes con la propuesta de que Keiko Fujimori y P. P. Kuczynski podían ser considerados los candidatos de la derecha, y sugiere que los votantes de ambas opciones electorales podrían presentar cierta afinidad ideológica. Por otro lado, los votantes de Alejandro Toledo, un candidato propuesto como de centro, podían migrar su voto con mayor facilidad hacia Humala en lugar de hacia Keiko Fujimori. Como se mencionó en la revisión bibliográfica, Alejandro Toledo fue, entre 1999 y 2000, la figura anti-fujimorista más visible y poco tiempo antes de la segunda vuelta de 2011, el propio Toledo manifestaría que lo más adecuado para la democracia peruana era votar por Ollanta Humala (Toledo, 2011). Es importante notar además, que un porcentaje considerable $(10.2 \%$ de la muestra) votó por Pedro Pablo Kuczynski en la primera vuelta electoral y vició su voto en la segunda, lo que expresaría un rechazo hacia las opciones políticas que pasaron a la segunda vuelta (Humala y $\mathrm{K}$. Fujimori) por parte de un subgrupo de los simpatizantes de Kuczynski.

\section{Rigidez cognitiva, ideología política y comportamiento electoral en la segunda vuelta}

Variables cognitivas como la intolerancia a la ambigüedad o la necesidad de cierre parecen no ser suficientes, por sí solas, para explicar los cambios en el comportamiento político. Estas variables cognitivas subyacen a una ideología política conservadora expresada, en el caso de este estudio, a través del RWA y la orientación política de derecha. Son estas variables ideológicas las que sí parecen tener, a la luz de los resultados, una capacidad explicativa sobre el comportamiento electoral. 
Podemos sugerir incluso que, en el caso específico de la elecciones presidenciales de 2011, es la orientación política de derecha la que puede explicar mejor las preferencias electorales. Si observamos la Tabla 4, el voto de izquierda favorece claramente a Ollanta Humala, mientras que el voto de derecha favorece a Keiko Fujimori. Pese a ello, se observa que un $17.3 \%$ de participantes que pudiendo ser ubicados como de derecha, manifestaron haber votado por Ollanta Humala.

Con respecto al RWA, parece ser que menores niveles de autoritarismo favorecieron el voto hacia Humala, lo que no se observa de manera tan clara cuando existen mayores niveles de autoritarismo (ver Tabla 3). En ese sentido, el voto hacia O. Humala y Keiko Fujimori es bastante más homogéneo en el caso del conglomerado denominado "Más autoritarios" que en el caso de los "Menos autoritarios".

\section{Conservadurismo de derecha y reacciones emocionales después de la segunda vuelta}

La primera hipótesis de este estudio, $\left(H_{1}\right)$ que proponía que la intolerancia a la ambigüedad y la necesidad de cierre cognitivo, correlacionadas entre sí de forma positiva, debían ejercer ambas, una influencia directa sobre el RWA y sobre la orientación política de derecha, se cumplió solo en parte. Intolerancia a la ambigüedad y necesidad de cierre cognitivo están asociadas positivamente (ver Figuras 1 y 2); sin embargo, solo ejercen influencia directa sobre el RWA y no así sobre la orientación política de derecha (ver Figuras 1 y 2). La segunda hipótesis $\left(H_{2}\right)$ que proponía que el RWA debía ejercer una influencia directa sobre la orientación política de derecha se cumplió en ambos diagramas estructurales (ver Figuras 1 y 2). Finalmente, la tercera hipótesis $\left(H_{3}\right)$ que planteaba que tanto el RWA como la orientación política de derecha debían ejercer una influencia directa sobre las reacciones emocionales de miedo, desprecio y asco luego de la victoria electoral de Ollanta Humala, y a la vez, una influencia inversa sobre las reacciones emocionales de alegría e interés, tuvo que ser modificada luego del contrastar el modelo hipotético (Modelo 1). 
Al proponer y contrastar el modelo alternativo (Modelo 2), se puede sostener que el RWA recibe la influencia conjunta de la intolerancia a la ambigüedad y la necesidad de cierre cognitivo, y esto es coherente con los resultados de investigaciones previas que han relacionado la rigidez cognitiva con variables ideológicas vinculadas al conservadurismo político como el RWA u otras (e. g., Durrheim, 1998; Federico et al., 2005; Jost et al., 2009; Jost et al., 2003; Matthews et al., 2009; Roets \& Van Hiel, 2010; Rottenbacher et al., 2011; Van Hiel et al., 2010; Van Hiel et al., 2004). Por otro lado, en ambos modelos se propuso que el RWA ejercería una influencia directa sobre la orientación política de derecha lo que pudo ser corroborado en los datos (ver Figura 2).

En el modelo alternativo se propuso que la orientación política de derecha influiría directamente sobre el miedo y el desprecio luego del triunfo de Ollanta Humala e inversamente sobre la alegría luego de la segunda vuelta. Esto también fue corroborado en el Modelo 2, que mostró además, el rol central que ocupa el miedo como una emoción que puede explicar los cambios en otras reacciones emocionales negativas como el desprecio y el asco, y en emociones positivas como la alegría. Finalmente, se pudo observar que el desprecio ejerce una influencia directa de alta intensidad sobre el asco, mientras la alegría lo hace sobre el interés (ver Figura 2). Esto que resulta coherente con la propuesta de Hodson y Costello (2007) sobre la relación entre el asco y el desprecio, y la de Izard $(1992,1991)$ acerca de la relación entre alegría e interés como emociones positivas.

En términos generales, se ha podido mostrar evidencia empírica que sostiene la idea central de este estudio: el continuo ideológico izquierda/ derecha recobró vigencia durante las elecciones presidenciales peruanas del año 2011, lo que se puede observar en el modelo alternativo (Modelo 2), cuando se aprecia la influencia de la orientación política de derecha sobre las reacciones emocionales positivas y negativas ante el triunfo de Ollanta Humala que, como se mencionó en la revisión bibliográfica, en el imaginario político de los limeńos, fue el candidato que estuvo vinculado con la izquierda desde su primera postulación a la presidencia en 2006 y durante la campaña electoral 2010-2011. 


\section{Conclusiones}

Se puede sostener que el conservadurismo politico de derecha, concebido como una estructura ideológica, presenta un escalamiento en las variables que lo constituyen, lo que corrobora la propuesta teórica de Jost et al. (2003) y los resultados de una investigación previa realizada en población limeña (Rottenbacher et al., 2011). Esto puede observarse tanto en el Modelo 1 como en el Modelo 2. Sin embargo, el buen ajuste obtenido por el Modelo 2 propone una organización psicológica de tres niveles. En el nivel más profundo (desde un punto de vista psicológico), se encuentran la intolerancia a la ambigüedad y la necesidad de cierre, variables cognitivas multipropósito (no necesariamente orientadas hacia fenómenos políticos) que expresan una rigidez cognitiva (Durrheim, 1998; Federico et al., 2005; Roets \& Van Hiel, 2010), y que según Jost et al. (2003) deben entenderse como necesidades epistémicas.

La adhesión hacia ideologías políticas conservadoras satisface estas dos necesidades, al brindar certeza, claridad, estructura y seguridad con respecto a la organización del mundo social (Jost et al., 2003). En el Modelo 2, el RWA representa una variable intermedia entre la rigidez cognitiva y la orientación política de derecha, esta última, una variable vinculada exclusivamente con temas políticos. El rol mediador del RWA deberá ser corroborado en futuras investigaciones, aunque es coherente con lo hallado por Rottenbacher et al. (2011).

Finalmente, es posible concluir, por lo menos en el contexto electoral que se vivió en el Perú durante 2011, y en especial en Lima, que la orientación política de izquierda influyó sobre el voto hacia Ollanta Humala y las reacciones emocionales positivas luego de su triunfo, mientras que una orientación política de derecha influyó sobre el voto hacia Keiko Fujimori y por consiguiente, sobre las reacciones emocionales negativas luego de su derrota electoral. De esta manera, es posible sostener que las categorías políticas de izquierda y derecha no han desaparecido de la cultura política limeña, sino que pueden reaparecer como categorías o representaciones cognitivas útiles para las personas, que les ayuden a clasificar o rotular a las diversas opciones políticas, 
a los candidatos y a sus simpatizantes, con la finalidad de simplificar y organizar la información social en un contexto político sumamente complejo y conflictivo, como lo fue el contexto electoral de 2011.

\section{Referencias}

Adorno, T., Frenkel-Brunswik, E., Levinson, D. \& Sanford, R. (1950). The Authoritarian Personality. Nueva York: Harper.

Altemeyer, B. (1981). Right-wing authoritarianism. Winnipeg: University of Manitoba.

Altemeyer, B. (1988). Enemies of freedom: Understanding right-wing authoritarianism. San Francisco: Jossey-Bass.

Altemeyer, B. (1998). The other "authoritarian personality". En M. Zanna (Ed.), Advances in experimental social psychology, 30, 47-91. Nueva York: Academic Press.

Altemeyer, B. (2004). Highly dominating, highly authoritarian personalities. The Journal of Social Psychology, 144(4), 421-447.

Arquero, J. \& McLain, D. (2010). Preliminary Validation of the Spanish Version of the Multiple Stimulus Types Ambiguity Tolerance Scale (MSTAT-II). The Spanish Journal of Psychology, 13(1), 476-484.

Bobbio, N. (1996). Derecha e izquierda. Razones y significados de una distinción política. Madrid: Taurus.

Bollen, K. (1989). A New Incremental Fit Index for General Structural Equation Models. Sociological Methods \& Research, 17(3), 303316.

Caballero, G. (2010, 24 de octubre). Grupos de izquierda radical apoyarán a Ollanta Humala en elecciones del 2011. El Comercio. Recuperado el 5 de marzo de http://elcomercio.pe/ politica/658694/noticia-grupos-izquierda-radical-apoyaranollanta-humala-elecciones-2011

Cohen, J. (1988). Statistical Power Analysis for the Behavioral Sciences. Hillsdale, N. J.: Lawrence Erlbaum Associates. 
Cottam, M., Dietz-Uhler, B., Mastors, E. \& Preston, T. (2004). Introduction to Political Psychology. Nueva Jersey: Lawrence Erlbaum Associates.

Crowson, H., Thoma, S. \& Hestevold, N. (2005). Is Political Conservatism Synonymous With Authoritarianism? The Journal of Social Psychology, 145(5), 571-592.

Dargent, E. (2011). ¿La misma Derecha? Recuperado el 5 de marzo de 2012 de http://eduardodargent.lamula.pe/tag/peru-elecciones2011-derecha-izquierda-keiko-fujimori-alejandro-toledo

Duckitt, J. \& Sibley, C. (2007). Right Wing Authoritarianism, Social Dominance Orientation and the Dimensions of Generalized Prejudice. European Journal of Personality, 21, 113-130.

Durrheim, K. (1998). The relationship between tolerance of ambiguity and attitudinal conservatism: a multidimensional analysis. European Journal of Social Psychology, 28, 731-753.

Espinosa, A. (2008). Decidiéndose por el mal menor. El rol de las emociones en las elecciones peruanas del 2006. Revista Psicología Politica de la Universidad de Valencia, 37, 47-70.

Federico, C., Golec, A. \& Dial, J. (2005). The Relationship between Need for Closure and Support for Military Action against Iraq: Moderating Effects of National Attachment. Personality and Social Psychology Bulletin, 31, 621-632.

Ferrándiz, J., Ibáñez, C. \& Espinosa, A. (2011). Racismo 2.0: expresiones de prejuicio en las redes sociales virtuales tras las elecciones generales de 2011. Revista Politai, 3, 75-83.

Fuchs, D. \& Klingemann, H. (1990). The left-right schema. En M. Jennings \& J. Van Deth, (Eds.), Continuities in Political Action: A Longitudinal Study of Political Orientations in Three Western Democracies (pp. 203-234). Berlin: Walter de Gruyter.

Fukuyama, F. (1992/2006). The end of history and the last man. Nueva York: Free Press.

Fukuyama, F. (1988/1990). ¿El Fin de la Historia? Estudios Públicos, 37, 5-31. Recuperado el 5 de marzo de 2012 de http://www. bioetica.org/umsa/produccion/fukuyama.pdf 
Greenberg, J. \& Jonas, E. (2003). Psychological Motives and Political Orientation-The Left, the Right, and the Rigid: Comment on Jost et al. (2003). Psychological Bulletin, 29(3), 376-382.

Hodson, G. \& Costello, K. (2007). Interpersonal Disgust, Ideological Orientations, and Dehumanization as Predictors of Intergroup Attitudes. Psychological Science, 18(8), 691-698.

Izard, C. (1992). Basic Emotions, Relations among Emotions and Emotion-Cognition Relations. Psychological Review, 99, 561-565. Izard, C. (1991). The Psychology of Emotions. Nueva York: Plenum Press. Jiménez, F. (2000). El Modelo Neoliberal Peruano: Limites, Consecuencias Sociales y Perspectivas. Documento de trabajo 184. Recuperado el 13 de febrero de 2012 de http://departamento.pucp.edu.pe/ economia/images/documentos/DDD184.pdf

Jost, J., Kruglanski, A. \& Simon, L. (1999). Effects of epistemic motivation on conservatism, intolerance, and other system justifying attitudes. En D. Thompson, M. Messick \& J. Levine (Eds.), Shared cognition in organizations: The management of knowledge (pp. 91-116). Mahwah: Erlbaum.

Jost, J., Glaser, J., Kruglanski, A. \& Sulloway, F. (2003). Political Conservatism as Motivated Social Cognition. Psychological Bulletin, 129(3), 339-375.

Jost, J. \& Hunyady, O. (2005). Antecedents and Consequences of System-Justifying Ideologies. Current Directions in Psychological Science, 14(5), 260-265.

Jost, J. (2006). Revisiting the End of Ideology Claims. An Emerging Psychological Paradigm for the Study of Ideology. Revista Psicología Politica de la Universidad de Valencia, 33, 75-100.

Jost, J., Federico, C. \& Napier, J. (2009). Political Ideology: Its Structure, Functions, and Elective Affinities. Annual Review of Psychology, 60, 307-337.

Keltner, D. \& Haidt, J. (1999). Social function of emotions at four level of analysis. Cognition \& Emotion, 13(5), 505-521.

Kline, R. (2005). Principles and practice of structural equation modeling (2da. edición). Nueva York: Guilford. 
Kuczynski, P.P. (Marzo, 2012). Declaraciones de Pedro Pablo Kuczynski a la prensa peruana. Recuperado el 4 de marzo de 2012 de http:// peru.com/actualidad/ppk-pide-votar-keiko-fujimori-deteneramenaza-noticia-6118

Marcus, G. \& MacKuen, M. (1993/2004). Anxiety, Enthusiasm, and the Vote: The Emotional Underpinnings of Learning and Involvement During Presidential Campaigns. En J. Jost \& J. Sidanius (Eds.), Political Psychology: Key Readings. Nueva York: Psychology Press.

Matthews, M., Levin, S., \& Sidanius, J. (2009). A Longitudinal Test of the Model of Political Conservatism as Motivated Social Cognition. Political Psychology, 30(6), 921-936.

McCann, S. (2009). Political Conservatism, Authoritarianism, and Societal Threat: Voting for Republican Representatives in U.S. Congressional Elections from 1946 to 1992. The Journal of Psychology, 143(4), 341-358.

McCann, S. (2008). Societal Threat, Authoritarianism, Conservatism and U.S. Death Penalty Sentencing (1977-2004). Journal of Personality and Social Psychology, 94, 913-923.

Mendoza, W. (2011). Las dos caras de "el milagro peruano". Demo. Suplemento del Semanario Punto EDU, 1(2), 1-8. Recuperado el 8 de febrero de 2012 de http://www.pucp.edu.pe/puntoedu/ dmdocuments/DEMO2.pdf

Napier, J. \& Jost, J. (2008). The "antidemocratic personality" revisited: a cross-national investigation of working class authoritarianism. Journal of Social Issues, 64, 595-617.

Oesterreich, D. (2005). Flight into Security: A new Approach and Measure of the Authoritarian Personality. Political Psychology, 26, 275-297.

Oficina Nacional de Procesos Electorales (ONPE) (2011a). Elecciones Generales 2011 Segunda Elección Presidencial, Resumen Nación. Recuperado el 3 de febrero de 2012 de http://www.web.onpe. gob.pe/modElecciones/elecciones/elecciones2011/2davuelta/ 
Oficina Nacional de Procesos Electorales (ONPE) (2011b). Elecciones Presidenciales 2011, Resumen Nación. Recuperado el 6 de marzo de 2012 de http://www.web.onpe.gob.pe/modElecciones/elecci ones/elecciones2011/1 ravuelta/

Panebianco, A. (1982). Modelos de Partido. Madrid: Alianza Editorial. Plutchik, R. (1980). Emotion: a psychoevolutionary analysis. Nueva York: Harper and Row.

Roets, A. \& Van Hiel, A. (2010). Item selection and validation of a brief, 15-item version of the Need for Closure Scale. Personality and Individual Differences, 50(1), 90-94.

Rottenbacher, J. M. \& Schmitz, M. (2012, en prensa). Conservadurismo político y tolerancia hacia comportamientos transgresores. Revista Psicología Politica de la Universidad de Valencia, 44, 1-26.

Rottenbacher, J. M., Espinosa, A. \& Magallanes, J. M. (2011). Analizando el prejuicio: bases ideológicas del racismo, el sexismo y la homofobia en una muestra de habitantes de la ciudad de Lima-Perú. Revista Psicologia Política de la Associação Brasileira de Psicologia Politica, 11(22), 225-246.

Rozin, P., Markwith, M. \& McCauley, C. (1994). Sensitivity to indirect contacts with other persons: AIDS aversion as a composite of aversion to strangers, infection, moral taint, and misfortune. Journal of Abnormal Psychology, 103, 495-504.

Ruiz, M., Pardo, A. \& San Martín, R. (2010). Modelos de Ecuaciones Estructurales. Papeles del Psicólogo, 31(1), 34-45.

Schaller, M., Park, J. \& Faulkner, J. (2003). Prehistoric dangers and contemporary prejudices. European Review of Social Psychology, 14, 105-137.

Schumacker, R. \& Lomax, R. (2004). A beginner's guide to structural equation modeling (2da. edición). Mahwah, NJ: Erlbaum.

Sidanius, J., Pratto, F., Van Laar, C. \& Levin, S. (2004). Social Dominance Theory: Its Agenda and Method. Political Psychology, 25(6), 845-880. 
Stephan, W. \& Stephan, C. (1993). Cognition and affect in stereotyping: Parallel interactive networks. En D. Mackie \& D. Hamilton (Eds.), Affect, cognition, and stereotyping: Interactive processes in group perception (pp. 111-136). Orlando: Academic Press.

Stephan, W. \& Stephan, C. (1996). Predicting prejudice. International Journal of Intercultural Relations, 20, 409-426.

Tanaka, M. (2011). La desigualdad en las ciencias sociales peruanas: itinerario y temas de agenda actual. En J. Cotler \& R. Cuenca (Eds.), Las desigualdades en el Perú: balances criticos (pp. 59-95). Lima: Instituto de Estudios Peruanos (IEP).

Thorisdottir, H., Jost, J., Liviatan, I. \& Shrout, P. (2007). Psychological Needs and Values Underlying Left-Right Political Orientation: Cross-National Evidence from Eastern and Western Europe. Public Opinion Quarterly, 71(2), 175-203.

Toledo, A. (2011, 26 de mayo). Toledo anunció su apoyo a Humala. Perú 21. Recuperado el 6 de marzo de 2012 de http://peru21. pe/noticia/763566/toledo-anuncio-su-apoyo-humala

Van Hiel, A., Onraet, E. \& De Pauw, S. (2010). The relationship between social-cultural attitudes and behavioral measures of cognitive style: A meta-analytic integration of studies. Journal of Personality, 78, 1765-1800.

Van Hiel, A., Pandelaere, M. \& Duriez, B. (2004). The impact of need for closure on conservative beliefs and racism: Differential mediation by authoritarian submission and authoritarian dominance. Personality and Social Psychology Bulletin, 30, 824-837.

Vela, J. C. (2006). La actuación de los medios y la construcción del escenario politico en los diarios: El Comercio, La República, Perú 21 y Correo. Elecciones presidenciales Perú 2006. Recuperado el 2 de marzo de 2012 de http://www.c3fes.net/docs/elecciones-mediosperu.pdf.

Velasco, K., Verkuyten, M., Weesie, J. \& Poppe, E. (2008). Prejudice towards Muslims in The Netherlands: Testing integrated threat theory. British Journal of Social Psychology, 47, 667-685.

Zakrisson, I. (2005). Construction of a short version of the RightWing Authoritarianism (RWA) scale. Personality and Individual Differences, 39, 863-872. 
Continuo ideológico izquierda/derecha / Rottenbacher

\section{Apéndice 1}

\section{Tabla 6. Resumen de los resultados de los tres análisis de conglomerados bietápicos $\left(^{*}\right)$}

\begin{tabular}{|c|c|c|c|c|c|c|c|c|}
\hline Variables & $\begin{array}{l}\text { Denominación de los } \\
\text { conglomerados }\end{array}$ & $n$ & $M E$ & $D E$ & $t$ & $g l$ & $p$ & $\Delta$ \\
\hline \multirow{2}{*}{$\begin{array}{l}\text { Intolerancia a } \\
\text { la ambigüedad }\end{array}$} & $\begin{array}{l}\text { 1. "Más cognitivamente } \\
\text { rígido"" }\end{array}$ & 114 & 3.59 & 0.58 & \multirow{2}{*}{11.056} & \multirow{2}{*}{253} & \multirow{2}{*}{$<.001$} & \multirow{2}{*}{1.09} \\
\hline & $\begin{array}{l}\text { 2. "Menos cognitivamente } \\
\text { rígidos" }\end{array}$ & 141 & 2.76 & 0.61 & & & & \\
\hline \multirow{2}{*}{$\begin{array}{l}\text { Necesidad } \\
\text { de cierre } \\
\text { cognitivo }\end{array}$} & $\begin{array}{l}\text { 1. "Más cognitivamente } \\
\text { rígidos" }\end{array}$ & 114 & 4.20 & 0.48 & \multirow{2}{*}{19.478} & \multirow{2}{*}{253} & \multirow{2}{*}{$<.001$} & \multirow{2}{*}{1.56} \\
\hline & $\begin{array}{l}\text { 2. "Menos cognitivamente } \\
\text { rígidos" }\end{array}$ & 141 & 3.01 & 0.49 & & & & \\
\hline \multirow{2}{*}{ RWA } & 1. "Menos autoritarios" & 177 & 2.45 & 0.54 & \multirow{2}{*}{-26.196} & \multirow{2}{*}{365} & \multirow{2}{*}{$<.001$} & \multirow{2}{*}{-1.62} \\
\hline & 2. "Más autoritarios" & 190 & 3.73 & 0.39 & & & & \\
\hline \multirow{2}{*}{$\begin{array}{l}\text { Orientación } \\
\text { política de } \\
\text { derecha }\end{array}$} & 1. "De derecha" & 189 & 4.36 & 0.55 & \multirow{2}{*}{28.851} & \multirow{2}{*}{364} & \multirow{2}{*}{$<.001$} & \multirow{2}{*}{1.67} \\
\hline & 2. "De izquierda" & 177 & 2.64 & 0.59 & & & & \\
\hline
\end{tabular}

$\left(^{*}\right.$ El análisis de conglomerados bietápicos (en dos fases) divide la muestra en subgrupos que se diferencian entre sí por los puntajes en determinadas variables. Por ello, como se observa en la Tabla 6, todas las diferencias de medias entre las variables utilizadas para formar los conglomerados resultan significativas al nivel $p<.001$. Además, según el estadístico $d$ de Cohen $(\Delta)$ se puede sostener que el tamaño de las diferencias es grande $(\Delta>0.80)$ (Cohen, 1988), aunque es mayor en el caso de la Orientación Política de Derecha y el RWA.

Recibido: 06 de marzo de 2012 Aceptado: 20 de junio de 2012 